\title{
Humor dalam Suasana Ramadan
}

\author{
M. Hermintoyo \\ hermintpujangga@gmail.com \\ Fakultas Ilmu Budaya, Universitas Diponegoro
}

\begin{abstract}
The existence of social media makes it easy for people to communicate and express themselves and so on. so there is an urge to express or inform something not only information but provide entertainment in the form of humor. In certain situations certain themes will emerge, for example during the month of Ramadan there will be humor themes related to events or activities related to Ramadan such as, when starving, breaking fast, sahur, forgiveness-forgiveness, holiday allowances, etc. . Humor is done in order to wait for the maghrib drum to be delivered so that there is activity during the fasting. In general, communicating humor gives each other humor that mobile phone users have. Creative journals used are usually play words that mean ambiguous.
\end{abstract}

Keywords: humor, play, ramadan, ambiguity.

\section{Intisari}

Adanya media sosial memudahkan orang untuk berkomunikasi dan mengekspresikan diri dst. sehingga ada dorongan mengekspresikan atau menginformasikan sesuatu tidak hanya informasi tetapi memberikan hiburan berupa humor. Pada situasi tertentu akan muncul tema-tema tertentu, misal pada bulan Ramadan maka akan muncul humor tema yang berkaitan dengan peristiwa atau aktivitas yang berhubungan dengan Ramadan seperti, saat kelaparan, berbuka, sahur, maaf-memaafkan, tunjangan hari raya,dst. . Humor dilakukan dalam rangka menunggu bedug maghrib yang disampaikan agar ada aktivitas selama perpuasa. Pada umumnya dalam berkomunikasi humor saling memberikan humor yang diumiliki pengguna hand phone. Diksi kreatif yang dipakai biasanya kata-kata plesetan yang bermakna ambigu.

Kata Kunci: Humor, plesetan, ramadan, ambigu.

\section{Pendahuluan}

Hadirnya media sosial memudahkan orang untuk berkomunikasi dan mengekspresikan diri tanpa terikat aturan penulisan dst. Hal ini mendorong orang untuk, mengekspresikan atau menginformasikan sesuatu tidak hanya informasi tetapi memberikan hiburan berupa humor. Pada situasi tertentu akan muncul tema-tema tertentu, misal pada bulan Ramadan maka akan muncul humor tema yang berkaitan dengan peristiwa atau aktivitas yang berhubungan dengan Ramadan. Humor dilakukan dalam rangka menunggu bedug maghrib yang disampaikan agar ada aktivitas selama perpuasa.

Hasdam (2008:1) menyatakan humor sangat penting bak asupan vitamin dalam tubuh agar dapat santai dan tersenyum. Humor juga bermanfaat dapat memperlancar aliran 
darah dan pernafasan, mengurangi stres dst. Humor bisa menjadikan suasana menyenangkan sehingga dicari bahkan mengembangkan ide kreatifnya. Ide kreatif itu dengan cara memelesetkan informasi.

Pemelesetan bahasa adalah segala sesuatu yang sudah benar menjadi tidak benar yang secara sengaja agar tercipta kelucuan sebagai sarana kekreatifan seseorang dalam mempermainkan makna. Sudarno (2004:xii) menjelaskan pelesetan atau imitation and parody, yaitu parodi yang isinya memelesetkan segala sesuatu yang telah mapan atau populer. Sebagai alat eskapisme dari kesumpekan keadaan.

Konsep kelucuan dari pemelesetan dan menjadi lucu jika antara penutur dan lawan tuturnya mempunyai pengetahuan yang sama tentang kata/ ungkapan serta makna aslinya yang dipelesetan. Penutur dan lawan tutur dalam komunikasi humor sudah paham bahwa dalam pelesetan tersebut ada makna keambiguitasannya, yaitu adanya kemungkinan ada dua pengertian atau lebih (lihat Chaer, 1990:107; Pateda, 1986:91. Karena bersifat ambiguitas, kadang-kadang menimbulkan keraguan, kekaburan, ketidakjelasan. Keambiguan itu akan terlihat dalam konteks yang dibicarakan (Hermintoyo, 1998:27). Wijana (2004) dalam tulisannya tentang bahasa kartun menjelaskan secara pragmatik, yaitu melihat pelanggaran maksim kerja sama. Pelanggaran itu mengakibatkan efek lucu. Kelucuan itu timbul karena aspek kebahasaan yang taksa atau ambigu.

Kemampuan memelesetkan makna kata menunjukkan penutur adalah orang yang terampi, cerdas dan menguasai linguistik. Hal ini karena kata/ ungkapan yang dipelesetkan menggunakan aturan sistematis dalam teori linguistik, seperti kemampuan memahami kaidah fonologi, morfologi, dan semantik. Disamping itu dalam aspek estetika diperlukan kaidah keindahan analogi-analogi yang digunakan sebagai gaya bahasa.

Fungsi lain, selain dipergunakan untuk humor yang menghibur dapat dimanfaatkan untuk mengkritik, mengingatkan, menyindir yang dilakukan tanpa beban; bagi pendengarnya bisa memberikan rangsangan rasa gembira dan pengetahuan. Danandjaja (dalam Wijana, 2003:3) menjelaskan humor berfungsi sebagai penglipur lara. Hal ini karena humor dapat menyalurkan ketegangan batin yang yang menyangkut ketimpangan norma masyarakat yang dapat dikendurkan melalui tawa. Humor merupakan suatu genre folklore yang sangat menarik. Walupun terkesan remeh dan bersifat santai, humor dapat dijadikan sebagai alat melihat kecerdasan seseorang atau penuturnya. Humor juga dapat dipergunakan untuk menjadikan pendengar merasa tergelitik perasaannya sehingga 
terdorong untuk tertawa. Sesuatu yang bersifat menggelitik perasaan itu dapat menimbulkan kejutan, keanehan, ketidakmasukakalan, kebodohannya, sifat pengecohan, kejanggalan, kenakalan, keisengan dst. Tertawa yang ditimbulkan oleh humor harus spontan dan bukan terlambat. Tertawa yang spontan sewaktu mendengar humor baru dapat terjadi apabila pendengarnya juga paham dengan konteksnya sehingga tidak perlu dijelaskan terlebih dahulu.

Hermintoyo (2011 menjelaskan keterampilan berhumor dapat dilakukan dengan proses perubahan kata secara morfologis disebutkan bisa melalui metatesis, substitusi, protesis, epentesis, paragoe, eferesis, sinkop, apakop, pelesapan. Selain itu ditemukan juga humor akibat ambigu/ ketaksaan baik ketaksaan leksikal maupun ketaksaan gramatikal serta gaya bahasanya. Berbicara gaya bahasa tentu berkaitan dengan stilistik yang berkaitan dengan makna. Dalam semantik termasuk dalam pembicaraan majas, yasitu menggunakan dengan bahasa yang konotatif atau makna tambahan.

Hobbess (dalam Helena, 2016:26-28) menjelaskan ada empat teori dasar yang menyebabkan sesuatu itu menjadi lucu. Pertama, ada aspek emosional yang kuat dalam humor yang menghasilkan respon bergairah; kedua, memiliki dampak tiba-tiba atau kejut yang berakibat mengeluarakan tawa atau perasaan senang; ketiga, ada masalah superior, yaitu timbul perasaan lebih unggul. Artinya ada rasa lebih cerdas dibanding dengan orang lain.

Humor diciptakan melalui permainan kata-kata yang makna kata-kata tersebut menjadi ambigu. Kelucuan dari humor adalah kejutan-kejutan kata akhir dari/ sebagai jawab yang ingin diungkapkan. Pembuat humor pasti ada kecerdasan dalam mengolah kata dalam kalimat yang disampaikan. Pilihan kata atau diksi yang digunakan biasanya menggunakan analogi tertentu dipas-paskan.

\section{Metode Penelitian}

Data penelitian ini diambil berdasar metode pustaka, yaitu mengambil data yang diambil di SMS/ WA hand phone. Data diambil sesuai kebutuhan dan dianggap sudah representatif. Teknik yang dilakukan adalah dengan teknik simak catat. Dengan langkah membaca berulang-ulang, disimak, dicatat dan diklasifikasikan.

Analisis yang digunakan adalah teori konsep humor yang bertumpu pada tiga teori utama, yakni teori ketidaksejajaran, pertentangan, dan teori pembebasan (Wijana, 
2003:20-28). Teori ketidaksejajaran mengemukakan bahwa humor secara tidak kongruen menyatukan dua makna atau penafsiran yang berbeda ke dalam suatu objek yang kompleks. Ketidak sejajaran bagian-bagian itu dipresepsikan secara tiba-tiba oleh penikmatnya. Wijana lebih lanjut dengan mengutip pendapat Wilman dikatakan“ ide-ide yang tidak konruen itu dapat disatukan dengan bunyi yang sama dan dapat pula salah satu diinferensikan dari yang lain, atau kedua-duanya dibayangkan dapat terjadi dalam kenyataan" Sesuatu yang tidak sejajar menurut paham ketidaksejajaran oleh penganut paham pertentangan dipandang sebagai fenomena pertentangan. Teori pembebasan merupakan penjelasan dari sudut dampak emosional. Humor tidak lain merupakan tipu daya emosional yang seolah mengancam, tetapi akhirnya terbukti tidak ada apa-apanya.

Konsep humorr dapat membuat kelucuan apabila mengandung satu atau lebih dari empat unsur, yaitu: 1) ada kejutan; 2) mengakibatkan rasa malu; 3) ketidakmasukakalan; 4) membesar-besarkan masalah. Keempat unsur itu dapat terlaksana melalui rangsangan verbal berupa kata-kata atau satuan-satuan bahasa yang sengaja dikreasi sedemikian rupa oleh penuturnya (Claire dalam Astuti, 2009:14). Pengkreasian itu dapat dilakukan dengan permainan bunyi yang berakibat bermakna taksa.; ada resepsi secara psikologis yang kuat dari pihak pendengarnya; pada umumnya harus disajikan dalam keadaan segar, tidak untuk dua kali apalagi untuk ketiga kali bagi pendengar yang sama.

Pendekatan semantik masalah humor berpusat pada ambiguitas yang dilaksanakan dengan mempertentangkan makna (M1) yang memiliki makna berbeda (M2). Ada yang dirasa salah bagi pembaca atau pendengar dari salah satu kata yang dianggap lucu (Astuti, 2009;13; Wijana,2003:23-28).

\section{Hasil dan Pembahasan}

Data 1. REQUEST

radio siaran klaten

Paijo: "Halo...po bener iki radio Klaten?"

"Halo...apa benar ini radio Klaten?

Penyiar: "Njih leres...wonten menopo?"

"Ya benar...ada apa?"

Paijo: "Akuyen request iso ra...?"

: Aku jika request bisa tidak...?"

Penyiar: Ngersakaken gendhing/ lagu menopo Pak Paijo?"

"Minta musik/ lagu apa Pak Paijo?"

Paijo: "Tulung setelno adzan maghrib...wetengku selak ngelih tenan ki..."

" Tolong stelkan adzan maghrib....perutku keburu lapar betul.." 
Data 1 kelucuan yang ditimbulkan ketidakumuman minta request musik/ lagu yang diharapkan dari penyiar ternyataq tidak sesuai, tetapi permintaan request adzan agar bisa berbuka karena tidak tahan menahan lapar. Kelaparan dalam berpuasa biasanya dihubungkan dengan waktu atau jam berbuka, biasanya di radio menyiarkan juga masa bedug maghrib tersebut. Untuk itu radio dipakai sebagai konteks tema berbuka. Di sinilah kejutan kata yang diharapkan bisa menimbulkan humor.

\section{Data2. CURHAT}

Nuwun sewu bade curhat...

Jujur, tak akoni, aku pancen due utang neng bank nggo nutup kebutuhan, tak kiro pdholah karo liyane

Tapi aku duwe niat nyaur kabeh utangku sampek lunas...janjiku nek wis duwe duit. Tapi aku ngroso isin tenan, pirang-pirang dino iki, saben jam 2 bengi ning ngarep omahku ono wong bengok-bengok....sahuuuuur....sahuuur

Aku khan isin, iki mesti kongkonan bank...aku kudu piye jall????

Permisi mau curhat.....

Jujur, saya akui, aku memang punya hutang di bank untuk menutup kebutuhan, aku kira samalah dengan yang lain

Tapi aku punya niat mengembalikan semua hutangku sampai lunas...janjiku jika sudah punya uang. Tapi aku merasa sangat malu, beberapa hari ini setiap jam 2 bengi di depan rumahku ada orang teriak-teriak....bayar hutangnya...bayar hutangnya. Saya khan malu, perasaanku pasti perintah dari bank..aku harus bagaima???"

Data dua aspek kelucuannya pada diksi yang ambigu atau bermakna ganda, yaitu kata sahur yang bermakna bangun untuk makan malam dalam suasana ramadan dengan makna plesetannya yang bermakna untuk mengembalikan hutangnya. Kejutan kata ambigu sangat efektif untuk memberikan efek lucu. Gaya penyampaian yang berupa curahan hati (curhat) sebagai pernyataan suasana ramadan dan ditutup dengan kata kejutan yang ambigu.

\section{Data 3. MEMBANGUNKAN SUAMI / ISTRI UNTUK SAHUR}

1. lakukan dengan hati yang ikhlas karena Allah

2. Usap kepala suami sambil cium keningnya

3. bisikan ke telinga suami sambil elus kepala suami

"Pah mau punya istri lagi gak?"

Dijamin suami langsung bangun dan siap sahur.

Sedangkan jika istri sulit bangun sahur lakukan seperti poin 1,2 dan ketiga dengan bisiukan "Mah izinkan papah nikah lagi ya..." 
Data 3. Dilakukan dengan nasihat yang baik dilakukan dengan ikhlas bagi istri maupun suami karena Allah dan ada kemesraan, tetapi di akhir nasihat itu ada kata kejutan untuk memberikan efek kelucuan dengan kata "Pah mau punya istri lagi nggak" atau "Mah izinkan papah menikah lagi ya..?" Ini menggambarkan bahwa seorang istri merasa bahwa laki-laki sebenarnya suka poligami, maka kata itu sangat tepat untuk memberikan efek lucunya. Siapapun laki-laki pasti akian senang jika diperbolehkan kawin lagi.

\section{Data 4. BUKA AWAL}

Kalau mau buka awal..bisa! Caranya jam 15.45 datang sajua ke praktik dokter...biasanya ada tulisan: Selama Ramadan buka jam 16.00. Beres khan ngikuti aturan dokter.

Data 4 efek kelucuannya dengan memelesetkan informasi yang dilakukan dokter pada saat buka praktik pada jam 16.00 buka. Kata buka inilah yang dimanfaatkan sebagai kata-kata humor ambigu. Buka yang artinya mulai buka praktik selama bulan puasa dan buka yang berarti buka puasa yaitu makan setelah berpuasa selama sehari yang ditandai berakhir saat maghrib.

\section{Data 5. SEKEDAR MENGINGATKAN}

Skedar mengingatkan agar bisa mengucap Selamat Hari Raya maka haruslah ada THR. Tanpa THR maka akan hanya berbunyi Selama Ai Aya...memang kurang sempurna.

Data 5. Kata kunci kejutannya pada kata THR (Tunjangan hari raya). THR adalah sesuatru yang ditunggu-tunggu bagi PNS, pegawai swasta. THR tidak membatasi hanya perusahaan yang muslim. THR sudah menjadi budaya bagi pegawai pemerintah dan swasta bahkan pekerja apa saja. Tujuan dari THR digunakan unbtuk merayakan hari raya, untuk beli pakaian, kebutuhan hari raya (masak, transport, ngecat rumah, memberi angpo). Kesempurnaan orang bekerja pasti dapat THR, tetapi jika tidak ada akan muncul kata-kata untuk menyenangkan hati. Bisa diungkapkan dengan nada humor Hari Raya menjadi Ai Aya...."

Data 6.

Orang buat kesalahan di Jakarta, eh...minta maafnya malah di Jawa (dengan gambar komedian Benyamin).

Kalimat ini berkesan menyindir orang Jawa. Mereka setahun hidup di Jakarta, beraktivitas, banyak hubungan dengan orang Jakarta tentunya banyak kesalahan-kesalahan yang 
dilakukan di Jakarta, tetapi orang Jawa beridulfitri dengan mudik pulang kampung di Jawa bermaaf-maafan bukannya dengan orang Jakarta.

\section{Data 7. INI CUMA MENGINGATKAN SAJA}

H-1 Nanti pemerintah akan mengumumkan hasiul sidang Isbad penentuan Hari Rayta Idul Fitri dimohon jangan ada yang bilang curang...dan menuntut Puasa Ulang...apalagi THR dikembalikan...Tolong ya...please.

Suasana politik juga dimanfaatkan untuk memberikan kesan humor, yaitu masaalah pilpres yang diberitakan banyak kecurangan dan berakhir kubu tertentu melakukan tuntutan dan dilakukan sidang. Efek kelucuannya terletak pada kata menuntut pada saat pemerintah mengumumkan hasil sidang isbad kemudian dianggap curang. Lebih parah lagi kalau sampai harus mengulang puasa dan mengembalikan THR. Kesan sindiran terhadap kubu tertentu yang menuntut pilpres harus diulang menjadi bahan kreativitas berhumor.

\section{Data 7. SUAMI NGEYEL}

Istri: "Pak bisa nggak, kalau buka puasa nggak usah pake rokok. Ganti kek pake kurma!" Suami: "Sudah dicoba berkali-kali mah...tapi nggak mau nyala?"

Dialog di atas menggambarkan seorang istri yang tidak suka suaminya merokok agar berbuka puasa tidak menggunakan rokok, tetapi buah kurma. Buah kurma merupakan ciri khas yang dihidangkan pada berbuka puasa di bulan ramadan. Efek humornya terlihat pada jawaban suaminya yang tidak nyambung dengan mengatakan sudah dilakukan, tetapi tidak mau nyala. Jawaban tersebut menunjukkan sebenarnya suami tetap mempertahankan untuk merokok.

Data 8. Buat yang mudik, jangan ngebut-ngebut ya...Ingat nenek moyang kita pelaut bukan pembalap

Kalimat yang membuat senyum-senyum adalah kalimat nasihat yang digunakan dengan menganalogikan keselamatan dalam perjalanan mudik. Analogi nenek moyang kita itu pelaut bukan pembalap. Artinya tidak tepat jika kita mudik kemudian jadi pembalap. Pelaut itu menjadi petrenang mestinya. Tujuan dari kalimat itu agar yang mudik berkendara tidak perlu ngebut dan selamat dalam perjalanan.

Data 9. Tiwas disediani jajan akeh lha kok jaluk sapurane lewat hp kabeh...??? 
Padahal sudah disediakan banyak makanan tetapi bermaaf-maafannya lewat hp semua Tradisi lebaran adalah bersilaturahmi dengan datang ke rumah, saling bermaaf-maafan, mencicipi hidangan dan makanan khas lebaran yang disediakan. Akan tetapi adanya teknologi (hp) suasana bersilaturahmi itu menjadi pudar, bermaaf-maafan cukup lewat hp, terutama dengan teman, kolega. Yang merasa hubungan keluarga dipastikan akan datang saling kunjung. Tradisi halalbihalal juga mempengaruhi silahturahmi ke rumah. Dengan datang ke acara halalbihalal sudah bisa saling memaafkan. Lebaran tidak lagi perlu persiapan makanan kecil dan besar. Jika dipersiapkan akan mubazir.

Data 10. Sebaiknya selama bulan puasa hindari makan di KFC dan Mc Donald...!!Karena cowok cewek penjualnya rada genit, baru datang sudah ditawari "Mau paha atau dada" "Mau di tempat atau mau di bawa"

Makanan yang digemari sekarang adalah makanan khas luar negeri yaitu masakan ayam di KFC dan McDonald bukan amasakan khas asli Indonesia, misal opor, ayam goreng. Data 10 beisi nasihat yang menggambarkan suasana di KFC dan McDonald pramusajinya genit memberikan pelayanan yang mengarah konotatif yaitu menawarkan paha atau dada, mau di tempat atau di bawa. Kesannya seakan menawarkan pramunikmat. Kalimat inilah yang memberikan efek kelucuan dengan menganalogikan dada, paha, dibawa atau di tempat yang bermakna ambigu.

\section{Simpulan}

Berdasar uraian di atas dapat disimpulkan:

Humor merupakan kebutuhan manusia dalam berkomunikasi dan mengekspresikan diri. Humor dapat mengendorkan ketegangan. Humor pada umumnya dibuat dengan memelesetkan kata yang berupa kejutan sebagai jawaban dari pernyataannya. Diksi atau kata-kata yang digunakan cenderung ambigu. Tema yang diangkat dalam suasana ramadan, bisa berupa rasa kelaparan, berbuka, sahur, tunjangan hari raya, maaf-memaafkan, mudik, perjalanan mudik, persiapan makanan kecil.

\section{Daftar Pustaka}

Astuti, Wiwik Dwi. 2009. Wacana Hiburan dalam "SMS Seru...!!”. Jakarta: Pusat Bahasa Deparetemen Pendidikan Nasional.

Chaer, Abdul.1990. Pengantar Semantik Bahasa Indonesia. Jakarta: Rineka Cipta. 
Hasdam, A. Sofyan. 2008. Humor Sehat: 100 Tawa Pilihan. Jakarta: Sofyan Hamdan Center.

Helena, Grace.2016.” Bentuk Humor pada Indovidgram.” Skripsi S-1 Program Ilmu Susastra Fakultas Ilmu Budaya Universitas Diponegoro Semarang.

Hermintoyo, M. 1998. "Ketaksaan dalam Bahasa Indonesia," dalam jurnal Lembaran Sastra. No. 23. hlm. 27-35. Semarang: Fakultas Sastra Universitas Diponegoro.

----2011. “Aspek Bunyi Sebagai Sarana Kreativitas Humor," dalam jurnal bidang kebahasaan dan kesusasteraan , Kajian Sastra. Vol.35. No.1 Januari. hlm.14-27. Semarang: Fakultas Ilmu Budaya Undip.

Pateda, Mansyur. 1986. Semantik Leksikal. Flores: Nusa Indah.

Sudarmo, Darminto M. 2004. Anatomi Lelucon di Indonesia. Jakarta: Kompas.

Wijana, I Putu. 2003. Kartun Studi: Tentang Permainan Bahasa. Yogyakarta: Ombak. 